\title{
High Voltage Bi-directional Flyback Converter for Capacitive Actuator
}

Thummala, Prasanth; Zhang, Zhe; Andersen, Michael A. E.

Published in:

Proceedings of EPE '13-ECCE Europe

Publication date:

2013

Link back to DTU Orbit

Citation (APA):

Thummala, P., Zhang, Z., \& Andersen, M. A. E. (2013). High Voltage Bi-directional Flyback Converter for Capacitive Actuator. In Proceedings of EPE '13-ECCE Europe IEEE.

\section{General rights}

Copyright and moral rights for the publications made accessible in the public portal are retained by the authors and/or other copyright owners and it is a condition of accessing publications that users recognise and abide by the legal requirements associated with these rights.

- Users may download and print one copy of any publication from the public portal for the purpose of private study or research.

- You may not further distribute the material or use it for any profit-making activity or commercial gain

- You may freely distribute the URL identifying the publication in the public portal

If you believe that this document breaches copyright please contact us providing details, and we will remove access to the work immediately and investigate your claim. 


\title{
High Voltage Bi-directional Flyback Converter for Capacitive Actuator
}

\author{
Prasanth Thummala, Zhe Zhang and Michael A. E. Andersen \\ TECHNICAL UNIVERSITY OF DENMARK \\ Oersteds Plads, Building 349 \\ Kongens Lyngby, Denmark \\ Tel.: +45-45255764. \\ E-Mail: pthu@elektro.dtu.dk \\ URL: http://www.ele.elektro.dtu.dk
}

\section{Keywords}

«High voltage power converters», «Switched-mode power supply », «Energy efficiency», «Actuator», «Electroactive materials».

\begin{abstract}
This paper presents a high voltage DC-DC converter topology for bi-directional energy transfer between a low voltage DC source and a high voltage capacitive load. The topology is a bi-directional flyback converter with variable switching frequency control during the charge mode, and constant switching frequency control during the discharge mode. The converter is capable of charging the capacitive load from $24 \mathrm{~V} \mathrm{DC}$ source to $2.5 \mathrm{kV}$, and discharges it to $0 \mathrm{~V}$. The flyback converter has been analyzed in detail during both charge and discharge modes, by considering all the parasitic elements in the converter, including the most dominating parameters of the high voltage transformer viz., self-capacitance and leakage inductance. The specific capacitive load for this converter is a dielectric electro active polymer (DEAP) actuator, which can be used as an effective replacement for conventional actuators in a number of applications. In this paper, the discharging energy efficiency definition is introduced. The proposed converter has been experimentally tested with the film capacitive load and the DEAP actuator, and the experimental results are shown together with the efficiency measurements.
\end{abstract}

\section{Introduction}

High voltage power converters are widely used in medical, airborne and space applications with voltage range from $5 \mathrm{kV}$ to $100 \mathrm{kV}$ and with a power level of few tens of watts to several hundred kilowatts. A number of applications require a capacitive load to be charged to several thousands of volts. Such applications include pulsed lasers, pulsed sonar equipment, photo flash systems, electric fences, and plasma research, which require high voltage DC power supplies to efficiently charge a large capacitive load to high voltage. Design of efficient high voltage power supplies is very vital in terms of selection of converter configuration, switching frequency, and control strategy. All these vital aspects are very closely related to the high voltage transformer used in the power converter.

The focus of our research is to develop high voltage DC power supplies for DEAP actuators, which are a special type of capacitive actuators made with dielectric electro active material, and require high voltage $(\sim 2.5 \mathrm{kV})$ at relatively low current, to fully actuate them. The dielectric electro active polymer is a thin silicon elastomer film $(\sim 20-80 \mu \mathrm{m})$ sandwiched between two metallic electrodes. Due to requirement of very high electric field strength of $>40 \mathrm{~V} / \mu \mathrm{m}$, the material needs high operating voltage to completely elongate the actuator [1]. DEAP technology has a wide potential in actuator, energy harvesting and sensor applications [2], [3] due to the material unique properties such as light weight, very low electrical power consumption, flexible nature, low noise and higher performance than competing technologies. DEAP actuators have some interesting applications in linear incremental motors, loud speakers, in-line heating valves, and wind turbine flaps, etc. [4], [5]. 
High voltage switch-mode power supplies for charging the capacitive loads have been implemented in [4]-[8]. In most of the papers the high output voltage was discharged by using a resistive load [7], an active discharge circuit [8], or with the high voltage probes $(4 \mathrm{kV}, 50 \mathrm{M} \Omega,<6 \mathrm{pF})$ [4], [5]. With these discharging methods, the reactive energy stored in the load capacitance is lost. If the output energy stored in the capacitive load is transferred back to the source, the lifetime of the source can be increased for battery powered applications. The energy stored in the load can be transferred to the source by discharging the capacitive load using a bi-directional DC-DC converter. The bi-directional flyback converters proposed in [9]-[11] perform the synchronous bi-directional operation to transfer the power in both directions. The operation and control of bi-directional flyback converter for charging and discharging a DEAP actuator is different from that of [9]-[11]. For this application, a new bi-directional flyback converter has been proposed and implemented to transfer the energy in both directions. It is to be noted that bi-directional in this application means either the energy flows from the source to the load or vice versa, but not at the same time.

\section{Table I: Specifications of the proposed bi-directional flyback converter}

\begin{tabular}{|c|c|c|}
\hline Parameter & Target & Achieved \\
\hline Input voltage $\left(V_{\text {in }}\right)$ & $24 \mathrm{~V}$ & $10-24 \mathrm{~V}$ \\
\hline Output voltage $\left(V_{\text {out }}\right)$ & $0-2500 \mathrm{~V}$ & $0-2500 \mathrm{~V}$ \\
\hline Peak charging efficiency $\left(\eta_{c p k}\right)$ & $\sim 90 \%$ & $\sim 85 \%$ \\
\hline Peak discharging efficiency $\left(\eta_{d p k}\right)$ & $\sim 80 \%$ & $\sim 79 \%$ \\
\hline $\begin{array}{l}117 \mathrm{nF} \text { capacitive load charging time } \\
\text { to charge from } 0 \mathrm{~V} \text { to } 2.5 \mathrm{kV}\left(t_{c h l}\right)\end{array}$ & $20 \mathrm{~ms}$ & $21 \mathrm{~ms}$ \\
\hline $\begin{array}{l}\text { DEAP actuator charging time } \\
\text { to charge from } 0 \mathrm{~V} \text { to } 2.5 \mathrm{kV}\left(t_{c h 2}\right)\end{array}$ & $20 \mathrm{~ms}$ & $22 \mathrm{~ms}$ \\
\hline $\begin{array}{l}117 \mathrm{nF} \text { capacitive load discharging time } \\
\text { to discharge from } 2.5 \mathrm{kV} \text { to } 0 \mathrm{~V}\left(t_{d c h l}\right)\end{array}$ & $20 \mathrm{~ms}$ & $16 \mathrm{~ms}$ \\
\hline $\begin{array}{l}\text { DEAP actuator discharging time } \\
\text { to discharge from } 2.5 \mathrm{kV} \text { to } 0 \mathrm{~V}\left(t_{d c h 2}\right)\end{array}$ & $20 \mathrm{~ms}$ & $17 \mathrm{~ms}$ \\
\hline DEAP actuator capacitance $\left(\mathrm{C}_{D E A P}\right)$ & NA & $117 \mathrm{nF}$ \\
\hline Charging switching frequency $\left(f_{s w c}\right)$ & NA & $\sim 10-60 \mathrm{kHz}$ \\
\hline Discharging switching frequency $\left(f_{s w d}\right)$ & NA & $\sim 25.6 \mathrm{kHz}$ \\
\hline $\begin{array}{l}\text { Primary peak current during charging } \\
\text { process }\left(I_{p p k} c h\right) / \text { discharging process }\left(I_{p p k d c h}\right)\end{array}$ & NA & $4.24 \mathrm{~A} / 5.3 \mathrm{~A}$ \\
\hline Stored energy in the capacitive load @ $2.5 \mathrm{kV}$ & NA & $\begin{array}{c}0.37 \mathrm{~J} \\
\text { [Equivalent to } 16 \mathrm{~W} \text { charging } \\
\text { power during } 21 \mathrm{~ms} \text {, and } \\
22 \mathrm{~W} \text { discharging power } \\
\text { during } 16 \mathrm{~ms} \text { ] }\end{array}$ \\
\hline
\end{tabular}

This paper focuses on the accurate analysis, design, component selection, and implementation of the 0-2.5 kV, low power bi-directional flyback converter. This paper illustrates a hard switched flyback converter topology that is capable of operating with reasonably good charging and discharging energy efficiencies over a wide operating output voltage range. The specifications of the bi-directional flyback converter are provided in Table I.

\section{Converter design and analysis}

In this section the high voltage bi-directional DC-DC converter, shown in Fig. 1 is discussed. High voltage unidirectional flyback converter for a normal resistive load is analyzed in [12] without considering all parasitic elements in the flyback converter. The converter operation during the charge and the discharge modes including all parasitic elements is analyzed in detail in this paper. Loss modeling of the proposed converter has been performed in [13] using the proposed accurate analysis. The approximated model of the flyback transformer from [14] either referred to primary or secondary is used in this paper for the analysis in each stage of charging and discharging processes (Fig. 3). 


\section{Topology}

Flyback converter topology had been widely used because of its relatively simple structure and better performance for single or multiple output applications. It can save the cost and volume compared with the other converters. Flyback converter is a well-suited topology for low power $(<200 \mathrm{~W})$ and high output voltage applications. Some high voltage applications of flyback converter are in cathode ray tube (CRT) for televisions, monitors and in xenon flash lamps for exciting the xenon gas.

The power stage of Fig. 1a can be divided into three parts: primary stage, high voltage flyback transformer and secondary stage. The primary stage consists of a DC voltage source, input capacitor $C_{i n}$, and low voltage MOSFET $M_{1}$. The flyback transformer with $1: n$ turns ratio is provided with an air gap, to store the energy in the magnetizing winding when the switch $M_{1}$ is turned ON. In the transformer model shown in Fig. $1 \mathrm{~b}, L_{m p}, C_{p}, C_{i n t}, C_{s}, L_{l k p}, L_{l k s}, R_{p}$, and $R_{s}$ represent the primary magnetizing inductance, primary self-capacitance, interwinding capacitance, secondary selfcapacitance, primary and secondary leakage inductances, primary DC resistance, and secondary DC resistances, respectively. The secondary stage consists of high voltage MOSFET $M_{2}$, high voltage diode $D_{2}$, which is required as the body diode of $M_{2}$ has very high reverse recovery time $\left(t_{r r}=2.8 \mu \mathrm{s}\right)$, another high voltage diode $D_{b}$ added in series with the drain of $M_{2}$, to block the body diode of $M_{2}$ during the discharging process, and a high voltage capacitive load $C_{\text {out }}$.

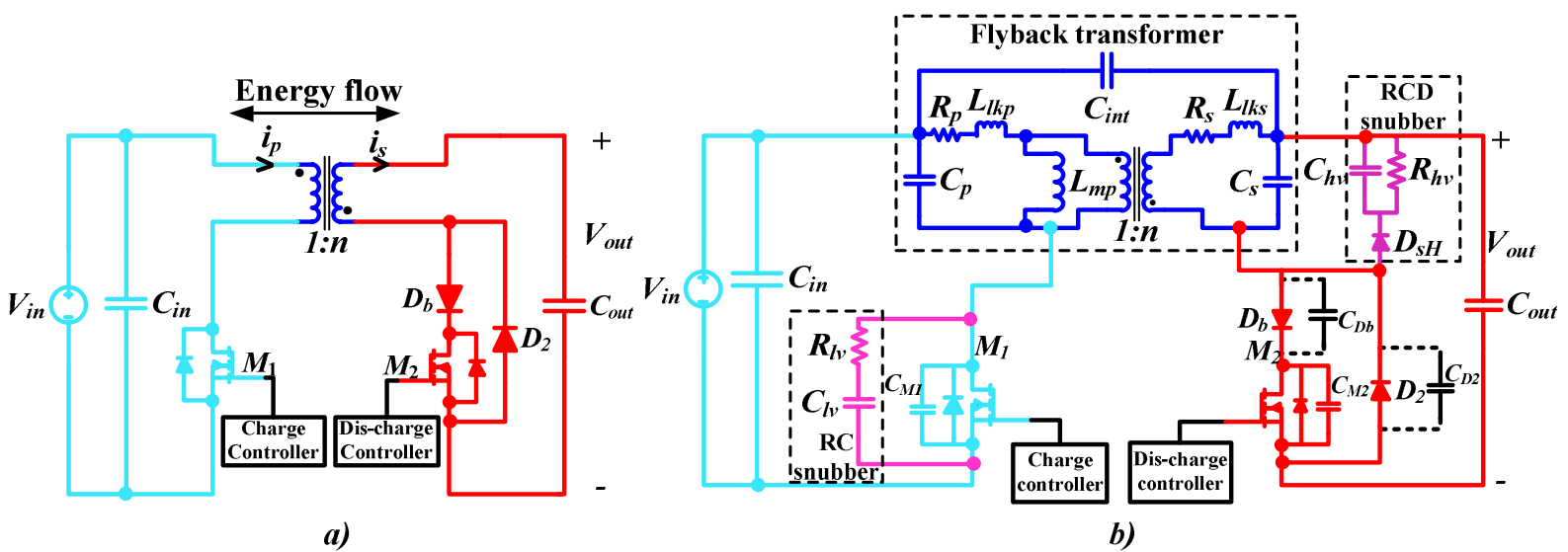

Fig. 1: Circuit configuration of the high voltage bi-directional flyback converter $(a)$; with equivalent transformer model, and RC snubber on low voltage side and RCD snubber on high voltage side $(b)$.

If a snubber circuit is not used in the flyback converter, then the stored energy in the leakage inductance is dissipated in the MOSFET resulting in large voltage spikes across it. In this capacitor charging application, on the primary side only a RC snubber has been used which can damp the high frequency oscillations in the drain voltage waveform, when the switch is OFF. The RCD snubber on the low voltage side can be skipped by either using an overrated low voltage MOSFET $M_{1}$ or by reducing the transformer leakage inductance. The stray capacitance of the transformer contributes to capacitive switching loss. We are investigating how to reduce both the leakage inductance and stray capacitance of the flyback transformer, and to make a trade-off between them for this high voltage capacitor charging application [13]. On the high voltage side a RCD snubber has been used to protect the high voltage MOSFET $M_{2}$ from the voltage spikes due to the secondary leakage inductance during discharging. As the maximum drain voltage of $M_{2}$ used in the converter is $4 \mathrm{kV}$, and with $24 \mathrm{~V}$ as input voltage and $\mathrm{n}=25$ as the turns ratio, the maximum drain voltage of $M_{2}$ excluding the voltage increase due to secondary leakage inductance, at $2.5 \mathrm{kV}$ output voltage is $3.1 \mathrm{kV}$. If the leakage inductance of the flyback transformer secondary is considered, the voltage seen by the drain of $M_{2}$ will be higher than by a factor of $\left[I_{s p k} \cdot\left(\sqrt{\frac{C_{\mathrm{sec} 2}}{L_{l k s}}-\left(\frac{R_{s}}{2 L_{l k s}}\right)^{2} C_{\mathrm{sec} 2}^{2}}\right)^{-1}\right]($ see (12)). Even though a passive snubber (RC or RCD) protects the MOSFET, it results in high power loss. To eliminate this power loss, active snubber circuits can be used at the cost of extra components. The circuit configuration of the practical 
flyback converter with the transformer equivalent model and the low and high voltage snubber circuits is shown in Fig. $1 b$.

\section{Converter analysis during charging process}

A soft-switched flyback converter is analyzed in [6] for high voltage capacitor charging application. While charging the capacitive load the proposed converter operates in the boundary mode (boundary between CCM and DCM), with peak current control using LT3751 [15]. The MOSFET $M_{1}$ is turned OFF when the primary current reaches the peak current $I_{p p k}$. The waveforms of the converter during the charge operation are shown in Fig. 2a. In general, self-capacitance of the transformer low voltage winding $\left(C_{p}\right)$ is very small compared to that of the high voltage winding, and hence can be neglected. One complete switching period $T_{s}$, during the charge mode can be divided into four stages. These stages operate continuously until the desired output voltage is reached. The first stage will begin after the transformer primary has finished storing the energy or when the primary MOSFET is turned OFF.

\section{Stage $1\left[t_{0}<t \leq t_{1}\right]$}

During this stage the MOSFET $M_{1}$ is OFF and the high voltage diode $D_{2}$ is blocked. The equivalent parasitic capacitance referred to the primary side $\left(C_{p r i}\right)$ when both the switch $M_{1}$ and the diode $D_{2}$ are OFF, is the parallel combination of the output capacitance of $M_{1}$, the transformer secondary selfcapacitance referred to the primary side, and the equivalent reflected parasitic capacitance of high voltage diodes ( $M_{2}$ is OFF during the charging process), and is given by

$$
C_{p r i}=\left[C_{M_{1}}+\left(C_{s}+C_{D_{2}}+\frac{C_{D_{b}} C_{M_{2}}}{C_{D_{b}}+C_{M_{2}}}\right) n^{2}\right]
$$

The magnetizing current $i_{p}$ charges the equivalent parasitic capacitance $C_{p r i l}=C_{p r i}$ in a resonant manner. The current through the magnetizing inductance $L_{m p}$ is $\left(i_{C_{p r i 1}}(t)=-i_{p}(t)\right)$

$$
i_{p}(t)=-C_{p r i 1} e^{-\alpha_{0 C}\left(t-t_{0}\right)}\left[\left(K_{0 C} \beta_{0 C}-V_{i n} \alpha_{0 C}\right) \cos \left(\beta_{0 C}\left(t-t_{0}\right)\right)-\left(K_{0 C} \alpha_{0 C}+V_{i n} \beta_{0 C}\right) \sin \left(\beta_{0 C}\left(t-t_{0}\right)\right)\right]
$$

The voltage across the transformer primary winding is

$$
\begin{aligned}
& V_{C_{p r i 1}}(t)=e^{-\alpha_{0 C}\left(t-t_{0}\right)}\left[V_{\text {in }} \cos \left(\beta_{0 C}\left(t-t_{0}\right)\right)+K_{0 C} \sin \left(\beta_{0 C}\left(t-t_{0}\right)\right)\right] ; V_{C_{p r i}}\left(t_{0}\right)=V_{i n} ; V_{C_{p r i 1}}\left(t_{1}\right)=\frac{-\left(V_{\text {out }}\left(t_{0}\right)+V_{H V d}\right)}{n} \\
& \alpha_{0 C}=\frac{R_{P}}{2 L_{m p}} ; \beta_{0 C}=\sqrt{\left(\frac{1}{L_{m p} C_{p r i 1}}-\alpha_{0 C}^{2}\right)} ; K_{0 C}=\frac{1}{\beta_{0 C}}\left(V_{i n} \alpha_{0 C}-\frac{I_{p p k}}{C_{p r i 1}}\right) ; i_{p}\left(t_{0}\right)=i_{p}\left(t_{1}\right)=i_{M_{1}}\left(t_{0}\right)=I_{p p k} ; i_{M_{1}}\left(t_{1}\right)=0
\end{aligned}
$$

\section{Stage $2\left[t_{1}<t \leq t_{2}\right]$}

During this stage the voltage across the primary winding of the transformer is clamped to the reflected voltage of $-\left(V_{\text {out }}\left(t_{0}\right)+V_{H V d}\right) / n$. The diode in the secondary side is turned-ON and the magnetizing current flows to the secondary side, and delivers the energy stored in $L_{m p}$ to the output capacitor $C_{\text {out }}$.

The primary leakage and secondary currents, and voltage across drain of $M_{1}$, and the output voltage are

$$
\begin{aligned}
& i_{\text {lkp }}(t)=I_{\text {ppk }} e^{-\alpha_{2 C}\left(t-t_{1}\right)}\left[\cos \left(\beta_{2 C}\left(t-t_{1}\right)\right)-\frac{\alpha_{2 C}}{\beta_{2 C}} \sin \left(\beta_{2 C}\left(t-t_{1}\right)\right)\right] ; V_{M_{1}}(t)=V_{\text {in }}+\frac{\left(V_{\text {out }}\left(t_{1}\right)+V_{H V d}\right)}{n}+\frac{I_{p p k}}{\beta_{2 C} C_{M_{1}}} e^{-\alpha_{2 C}\left(t-t_{1}\right)} \sin \left(\beta_{2 C}\left(t-t_{1}\right)\right) \\
& i_{\mathrm{s}}(t)=C_{\text {out }} e^{-\alpha_{1 C}\left(t-t_{1}\right)}\left[\left(K_{1 C} \beta_{1 C}-\left(V_{\text {out }}\left(t_{1}\right)+V_{H V d}\right) \alpha_{1 C}\right) \cos \left(\beta_{1 C}\left(t-t_{1}\right)\right)-\left(K_{1 C} \alpha_{1 C}+\left(V_{\text {out }}\left(t_{1}\right)+V_{H V d}\right) \beta_{1 C}\right) \sin \left(\beta_{1 C}\left(t-t_{1}\right)\right)\right]+\frac{i_{l l p}(t)}{n} \\
& V_{\text {out }}(t)=\left\{e^{-\alpha_{1 C}\left(t-t_{1}\right)}\left[\left(V_{\text {out }}\left(t_{1}\right)+V_{H V d}\right) \cos \left(\beta_{1 C}\left(t-t_{1}\right)\right)+K_{1 C} \sin \left(\beta_{1 C}\left(t-t_{1}\right)\right)\right]-V_{H V d}\right\} ; \alpha_{1 C}=\frac{R_{s}+r_{H V d}}{2\left(L_{m s}+L_{l l s}\right)} ; \alpha_{2 C}=\frac{R_{p}}{2 L_{l l p p}} \\
& \beta_{1 C}=\sqrt{\left(\frac{1}{\left(L_{\text {ms }}+L_{\text {lls }}\right) C_{\text {out }}}-\alpha_{1 C}^{2}\right)} ; \beta_{2 C}=\sqrt{\left(\frac{1}{L_{l l p} C_{M_{1}}}-\alpha_{2 C}^{2}\right)} ; K_{1 C}=\frac{1}{\beta_{1 C}}\left(\left(V_{\text {out }}\left(t_{1}\right)+V_{H V d}\right) \alpha_{1 C}+\frac{I_{\text {spk }}}{C_{\text {out }}}\right)
\end{aligned}
$$


where $V_{H V d}$ and $r_{H V d}$ are the voltage drop and resistance of the high voltage diode $\left(D_{2}\right.$ or $\left.\mathrm{D}_{b}\right)$ respectively. This stage ends when the secondary current falls to $0 \mathrm{~A}$, and $C_{p r i 2}=C_{M_{1}}$ (Fig. 3).

\section{Stage $3\left[t_{2}<t \leq t_{3}\right]$}

This stage occurs after the energy stored in $L_{m p}$ is completely transferred to the output capacitor $C_{\text {out }}$. In this stage the output capacitance of $M_{1}$ resonates with the magnetizing inductance $L_{m p}$ by bringing the voltage across $M_{1}$ close to $0 \mathrm{~V}$. In this stage, the equivalent reflected capacitance $C_{p r i 3}=C_{p r i 1}=C_{p r i}$ discharges through $M_{1}$ and $i_{C_{p r i}}(t)=-i_{p}(t)$.

The current through the magnetizing inductance and voltage across the primary winding are

$$
\begin{aligned}
& \left.i_{p}(t)=e^{-\alpha_{0 C}\left(t-t_{2}\right)}\left(\frac{-\left(V_{\text {out }}\left(t_{2}\right)+V_{H V d}\right)}{n}\right)\right)\left[\frac{1}{L_{m p} \beta_{0 C}} \sin \left(\beta_{0 C}\left(t-t_{2}\right)\right)\right] \\
& V_{C_{p r i 3}}(t)=e^{-\alpha_{0 C}\left(t-t_{2}\right)}\left(\frac{-\left(V_{\text {out }}\left(t_{2}\right)+V_{H V d}\right)}{n}\right)\left[\cos \left(\beta_{0 C}\left(t-t_{2}\right)\right)+\frac{\alpha_{0 C}}{\beta_{0 C}} \sin \left(\beta_{0 C}\left(t-t_{2}\right)\right)\right] ; V_{C_{\text {pri }}}\left(t_{3}\right)=V_{\text {in }}
\end{aligned}
$$

The voltage across MOSFET $M_{1}$ is

$$
V_{M_{1}}(t)=V_{\text {in }}+V_{C_{p r i 3}}(t) ; V_{M_{1}}\left(t_{3}\right)=0
$$

By solving (5) and (6), and using $\alpha_{0 C}$ and $\beta_{0 C}$ from (3)

$$
\sin \left(\beta_{0 C}\left(t_{3}-t_{2}\right)\right)=G \cdot \frac{\beta_{0 C}}{w_{0 C}^{2}}\left[\alpha_{0 C}+\sqrt{\frac{w_{0 C}^{2}}{G^{2}}-\beta_{0 C}^{2}}\right] ; G=\frac{V_{\text {in }} \cdot n}{\left(V_{\text {out }}\left(t_{2}\right)+V_{H V d}\right) e^{-\alpha_{0 C}\left(t_{3}-t_{2}\right)}} ; w_{0 C}=\sqrt{\frac{1}{L_{m p} C_{p r i 3}}}
$$

The peak negative amplitude of the equivalent capacitor $C_{p r i 3}$ current at the time $t_{3}$ is

$$
\left|i_{C_{p r i 3}}\left(t_{3}\right)\right|=\frac{V_{i n}}{L_{m p}}\left[\frac{R_{P} C_{p r i 3}}{2}+\frac{1}{w_{0 C}} \sqrt{G^{2}-\frac{\beta_{0 C}^{2}}{w_{0 C}^{2}}}\right]
$$

\section{Stage $4\left[t_{3}<t \leq T_{s}\right]$}

Stage 4 begins when $M_{1}$ is turned-ON by the controller under ZVS conditions. The current through the MOSFET $M_{1}$ flows in the negative direction (Fig. 2a) through its body diode for a short time, and then it continue to flow through $M_{1}$. The currents through $C_{p r i 4}$, transformer primary and MOSFET $M_{1}$ are

$$
\begin{aligned}
& i_{C_{p r i 4}}(t)=C_{p r i 4} e^{-\alpha_{3 C}\left(t-t_{3}\right)}\left[\frac{i_{C_{p r i 3}}\left(t_{3}\right)}{C_{p r i 4}} \cos \left(\beta_{3 C}\left(t-t_{3}\right)\right)-\left(K_{3 C} \alpha_{3 C}+\left(V_{C_{p r i}}\left(t_{3}\right)-V_{i n}\right) \beta_{3 C}\right) \sin \left(\beta_{3 C}\left(t-t_{3}\right)\right)\right] \\
& i_{p}(t)=\left[\frac{V_{i n}}{R_{p}+r_{d s o n 1}}+\left(i_{p}\left(t_{3}\right)-\frac{V_{i n}}{R_{p}+r_{\text {dson }}}\right) e^{-\frac{R_{p}+r_{\text {dopon }}}{L_{m p}+t_{l l p}}\left(t t_{3}\right)}\right]-\frac{L_{l k p}}{L_{m p}} i_{C_{p r i}}(t) ; i_{M_{1}}(t)=i_{p}(t)+i_{C_{p r i 4}}(t) \\
& \alpha_{3 C}=\frac{r_{d s o n 1}}{2 L_{l k p}} ; \beta_{3 C}=\sqrt{\left(\frac{1}{L_{l k p} C_{p r i 4}}-\alpha_{3 C}^{2}\right)} ; K_{3 C}=\frac{1}{\beta_{3 C}}\left(\left(V_{C_{p r i 3}}\left(t_{3}\right)-V_{\text {in }}\right) \alpha_{3 C}+\frac{i_{C_{p r i 3}}\left(t_{3}\right)}{\left.C_{p r i 4}\right)}\right) ; C_{p r i 4}=n^{2} \cdot\left(C_{s}+C_{M_{2}}+C_{D_{2}}\right)
\end{aligned}
$$

\section{Converter analysis during discharging process}

The same controller LT3751 [15] is used in the proposed bi-directional flyback converter for discharging the capacitive load. During discharging process, the converter operates in the discontinuous conduction mode (DCM) with constant switching frequency. The converter waveforms during the discharging operation are shown in Fig. 2b. The capacitive load is discharged when the high voltage MOSFET $M_{2}$ is turned ON, and transfer the energy stored in the secondary magnetizing winding $L_{m s}$ to the source, through the body diode of $M_{1}$, when $M_{2}$ is OFF. As the output voltage discharges, the ON- 
time of the high voltage MOSFET $M_{2}$ increases, and OFF-time is constant with a value of $L_{m p} i_{p p k}$ dch $_{1} / V_{\text {in }}$. At the end of the discharging process $M_{2}$ is completely turned ON. The switching period $T_{s}$ during discharging operation can be divided into 5 stages. The Stage 1 begins once the secondary magnetizing inductance $L_{m s}$ of the transformer has finished storing the energy.
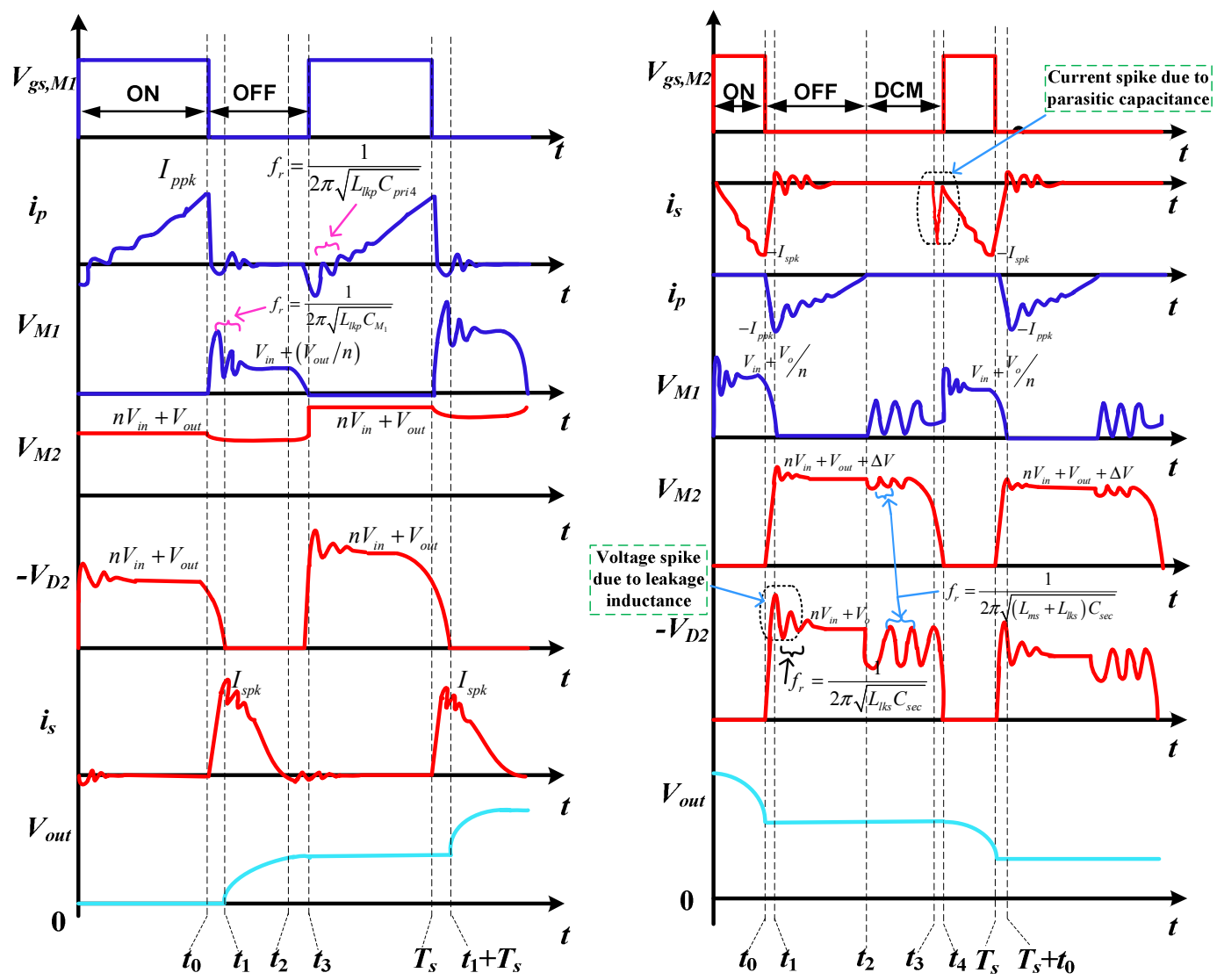

Fig. 2: Charging (a) and discharging (b) waveforms of the proposed converter.
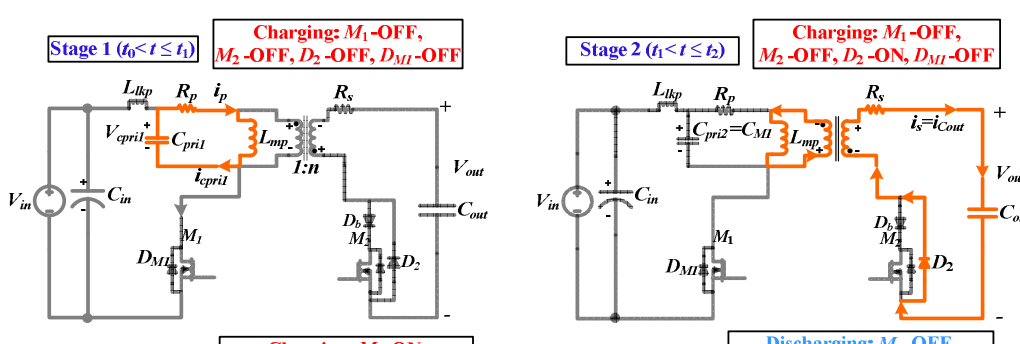

\begin{tabular}{c|c|} 
Charging: $M_{1}-\mathrm{OFF}$, \\
Stage $3\left(t_{2}<t \leq t_{3}\right)$ \\
$M_{2}$-OFF, $D_{2}-\mathrm{OFF}, D_{M I}$-OFF
\end{tabular}
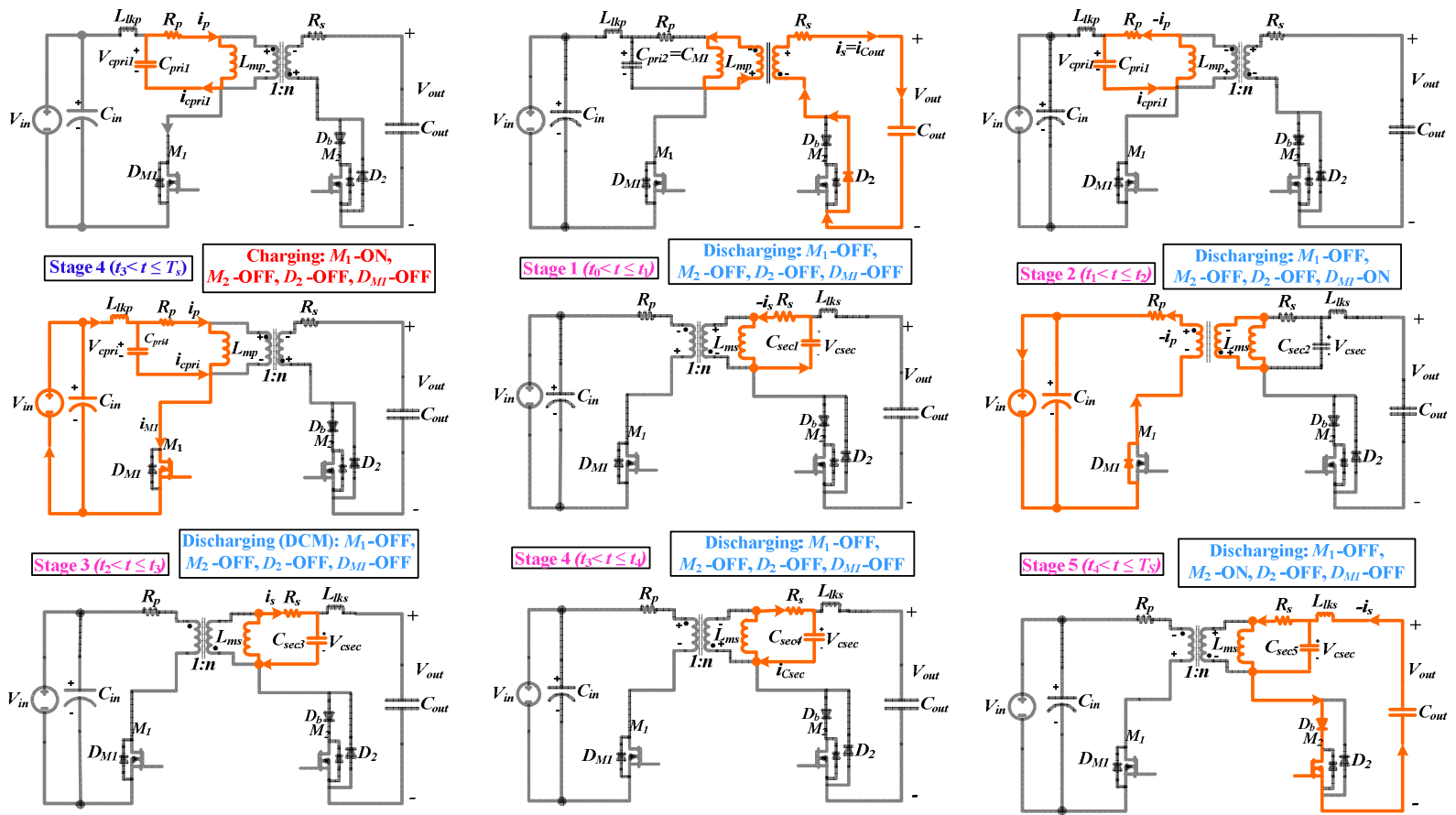

Fig. 3: All charging and discharging stages in one respective charging and discharging switching cycle 


\section{Stage $1\left[t_{0}<t \leq t_{1}\right]$}

The high voltage MOSFET $M_{2}$ is turned OFF at time $t=t_{0}$. The secondary magnetizing inductance $\left(L_{m s}\right)$ in series with the secondary leakage inductance $\left(L_{l k s}\right)$ resonates with the equivalent parasitic capacitance referred to the secondary side $C_{\text {sec }}$.

$$
C_{s e c}=C_{M_{2}}+C_{s}+C_{D_{2}}+\frac{C_{D_{b}} C_{M_{2}}}{C_{D_{b}}+C_{M_{2}}}
$$

The voltage across the transformer secondary winding and peak secondary current are

$$
\begin{aligned}
& V_{C_{\mathrm{sec}}}(t)=e^{-\alpha_{0 D}\left(t-t_{o}\right)}\left[V_{\text {out }}\left(t_{0}\right) \cos \left(\beta_{0 D}\left(t-t_{o}\right)\right)+K_{0 D} \sin \left(\beta_{0 D}\left(t-t_{o}\right)\right)\right] ; V_{C_{\text {sec }}}\left(t_{1}\right)=-n V_{\text {in }} \\
& \alpha_{0 D}=\frac{R_{S}}{2 L_{m s}} ; \beta_{0 D}=\sqrt{\left(\frac{1}{L_{m s} C_{\text {sec }}}-\alpha_{0 D}^{2}\right)} ; K_{0 D}=\frac{1}{\beta_{0 D}}\left(V_{\text {out }}\left(t_{0}\right) \alpha_{0 D}+\frac{I_{\text {spk }}}{C_{\text {sec }}}\right) \\
& I_{\text {spk }}=\sqrt{I_{\text {spk_design }}^{2}+\left(C_{\text {sec }} / L_{m s}\right) V_{\text {out }}^{2}}
\end{aligned}
$$

where $I_{s p k}$ is the actual secondary peak current, $I_{s p k \text { design }}$ is the design value of the secondary peak current or $M_{2}$ turn OFF current. If the energy stored in the equivalent parasitic capacitance $C_{\text {sec }}$ $\left(0.5 \cdot C_{s e c} V_{\text {out }}^{2}\right)$, is higher than the energy stored in the secondary winding inductance $L_{m s}\left(0.5 \cdot L_{m s} I_{\text {spk }}^{2}\right.$ des $)$, then the secondary peak current will be greater than the $M_{2}$ turn OFF current.

\section{Stage $2\left[t_{1}<t \leq t_{2}\right]$}

During this stage the voltage across the secondary winding of the transformer is clamped to $-n V_{\text {in }}$. The body diode of $M_{1}$ in the primary side conducts and the magnetizing current flows to the primary side, in the reverse direction delivering the output energy to the source. The stage ends when the primary current falls to $0 \mathrm{~A}$.

The secondary leakage and primary currents, and voltage across diode $D_{2}$ are

$$
\begin{aligned}
& i_{l k s}(t)=I_{\text {spk }} e^{-\alpha_{1 D}\left(t-t_{1}\right)}\left[\cos \left(\beta_{1 D}\left(t-t_{1}\right)\right)-\frac{\alpha_{1 D}}{\beta_{1 D}} \sin \left(\beta_{1 D}\left(t-t_{1}\right)\right)\right] ; \alpha_{1 D}=\frac{R_{s}}{2 L_{l k s}} \\
& V_{D_{2}}(t)=n V_{\text {in }}+V_{\text {out }}\left(t_{1}\right)+\frac{I_{s p k}}{\beta_{1 D} C_{\mathrm{sec} 2}} e^{-\alpha_{1 D}\left(t-t_{1}\right)} \sin \left(\beta_{1 D}\left(t-t_{1}\right)\right) ; \beta_{1 D}=\sqrt{\left(\frac{1}{L_{l k s} C_{\mathrm{sec} 2}}-\alpha_{1 D}^{2}\right)} \\
& i_{p}(t)=\left[\frac{V_{\text {in }}+V_{L V d}}{R_{p}}\left(1-e^{-\frac{R_{p}}{L_{\text {mp }}+L_{l k p}}\left(t-t_{1}\right)}\right)\right]-n \cdot i_{l k s}(t) ; V_{\text {out }}\left(t_{1}\right)=V_{\text {out }}\left(t_{0}\right) ; \mathrm{C}_{\mathrm{sec} 2}=\mathrm{C}_{\mathrm{M}_{2}}+\mathrm{C}_{s}+\mathrm{C}_{\mathrm{D}_{2}}
\end{aligned}
$$

\section{Stage $3\left[t_{2}<t \leq t_{3}\right]$}

This stage occurs when the primary current becomes zero. In this stage the converter operates in DCM. The secondary inductance $\left(L_{m s}\right)$ resonates with the equivalent secondary parasitic capacitance $C_{s e c 3}=C_{s e c}$. The voltage $V_{L V d}$ in (13) is the voltage drop of the body diode of $M_{1}$.

The voltages across $C_{s e c 3}$ and the drain of $M_{2}$, and the current through $C_{s e c 3}$ are

$$
\begin{aligned}
& V_{C_{\mathrm{sec}}}(t)=-\left[n\left(V_{\text {in }}+V_{L V d}\right)\right] \cdot e^{-\alpha_{2 D}\left(t-t_{2}\right)}\left[\cos \left(\beta_{2 D}\left(t-t_{2}\right)\right)+\frac{\alpha_{2 D}}{\beta_{2 D}} \sin \left(\beta_{2 D}\left(t-t_{2}\right)\right)\right] ; i_{C_{\mathrm{sec}}}(t)=C_{\mathrm{sec} 3} \frac{d V_{C_{\mathrm{sec}}}(t)}{d t} \\
& V_{M_{2}}(t)=V_{\text {out }}\left(t_{1}\right)+V_{C_{\mathrm{sec}}}(t)-V_{D_{b}}(t) ; V_{M_{1}}=V_{\text {in }}+\left(\frac{V_{C_{\mathrm{sec}}}(t)}{n}\right) ; \alpha_{2 D}=\alpha_{0 D} ; \beta_{2 D}=\sqrt{\left(\frac{1}{L_{m s} C_{\mathrm{sec} 3}}\right)^{2}-\alpha_{2 D}^{2}}
\end{aligned}
$$

\section{Stage $4\left[t_{3}<t \leq t_{4}\right]$}

In this stage the equivalent parasitic capacitance $C_{s e c}=C_{s e c}$ resonates with the secondary magnetizing inductance $L_{m s}$ by bringing the voltage across $M_{2}$ to $0 \mathrm{~V}$. 
The current through the equivalent parasitic capacitance $C_{\text {sec } 4}$ is given by

$$
i_{C_{\mathrm{sec}}}(t)=-e^{-\alpha_{0 D}\left(t-t_{3}\right)}\left[\frac{V_{C_{\mathrm{sec}}}\left(t_{3}\right)}{L_{m s} \beta_{0 D}} \sin \left(\beta_{0 D}\left(t-t_{3}\right)\right)\right]
$$

\section{Stage $5\left[t_{4}<t \leq T_{s}\right]$}

This stage begins when $M_{2}$ is turned-ON by the controller. The current not only flows through the magnetizing inductance $L_{m s}$, but also through the equivalent parasitic capacitance $C_{\text {sec } 5}=C_{s}+C_{D_{2}}$.

The currents through $C_{s e c}, L_{m s}$ and the MOSFET $M_{2}$, and the output voltage are

$$
\begin{aligned}
& i_{C_{\text {sec }}}(t)=-C_{\text {pris }} e^{-\alpha_{5 D}\left(t-t_{4}\right)}\left[\left(K_{5 D} \beta_{5 D}-V_{\text {out }}\left(t_{1}\right) \alpha_{5 D}\right) \cos \left(\beta_{5 D}\left(t-t_{4}\right)\right)-\left(K_{5 D} \alpha_{5 D}+V_{\text {out }}\left(t_{1}\right) \beta_{5 D}\right) \sin \left(\beta_{5 D}\left(t-t_{4}\right)\right)\right] \\
& V_{\text {out }}(t)=e^{-\alpha_{4 D}\left(t-t_{4}\right)}\left[\left(V_{\text {out }}\left(t_{1}\right)-V_{H V d}\right) \cos \left(\beta_{4 D}\left(t-t_{4}\right)\right)+K_{4 D} \sin \left(\beta_{4 D}\left(t-t_{4}\right)\right)\right]+V_{H V d} \\
& i_{s}(t)=\left[-C_{\text {out }} \frac{d V_{\text {out }}(t)}{d t}-\frac{L_{\text {lks }}}{L_{\text {ms }}} i_{C_{\mathrm{sec}}}(t)\right] ; i_{M_{2}}(t)=i_{s}(t)+i_{C_{\text {sec }}}(t) ; V_{\text {out }}\left(t_{4}\right)=V_{\text {out }}\left(t_{3}\right)=V_{\text {out }}\left(t_{2}\right)=V_{\text {out }}\left(t_{1}\right) \\
& \alpha_{4 D}=\frac{r_{\text {dson } 2}+R_{S}+r_{H V d}}{2\left(L_{m s}+L_{l k s}\right)} ; \beta_{4 D}=\sqrt{\left(\frac{1}{\left(L_{m s}+L_{l k s}\right) C_{o u t}}-\alpha_{4 D}^{2}\right)} ; K_{4 D}=\frac{1}{\beta_{4 D}}\left(\left(V_{o u t}\left(t_{1}\right)-V_{H V d}\right) \alpha_{4 D}-\frac{i_{C_{\text {sec }}}\left(t_{4}\right)}{C_{\text {out }}}\right) \\
& \alpha_{5 D}=\alpha_{1 D}, \beta_{5 D}=\sqrt{\left(\frac{1}{L_{l k s} C_{\mathrm{sec} 5}}-\alpha_{5 D}^{2}\right)} ; K_{5 D}=\frac{1}{\beta_{5 D}}\left(V_{\text {out }}\left(t_{1}\right) \alpha_{5 D}-\frac{i_{C_{\mathrm{sec}}}\left(t_{4}\right)}{C_{\mathrm{sec} 5}}\right)
\end{aligned}
$$

These stages operate continuously until the output voltage is discharged to $I_{s p k \_d c h} \sqrt{L_{m s} / C_{o u t}}$, which is the minimum voltage required to store the energy in $L_{m s}$ during the discharging process. At this point the MOSFET $M_{2}$ is completely ON, since the secondary current becomes zero, and $L_{m s}$ resonates with $C_{\text {out }}$.

\section{Controller description, component selection and transformer design}

Possible control techniques for the capacitor charging flyback converter have been discussed in [16]. For achieving $2.5 \mathrm{kV}$ bi-directional operation, the capacitor charger controller from Linear Technology [15] has been chosen as charge and discharge controllers.

\section{Variable frequency during charging and Constant frequency during discharging}

The primary inductance store the energy with constant ON-time at low output voltages, and with variable ON-time at high output voltages. The discharging time of $M_{1}$ decreases with the increase in the output voltage, which increases the switching frequency during the charging process. During discharging process, the control IC needs to sense the output voltage to operate in the boundary mode. But the controller LT3751 is not designed for wide input voltage variations $(2.5 \mathrm{kV}$ to $0 \mathrm{~V}$ is too wide operating range). So, we operated the IC in the start-up protection mode without giving the output voltage feedback to it, and the IC is operated with a constant switching frequency of $\sim 25.6 \mathrm{kHz}$.

\section{Component selection and Transformer design}

The components used for the implementation of the bi-directional flyback converter are given Table 2 . The flyback transformer is designed with the ETD 29 core and the measured parameters of the transformer are provided in Table 3. The transformer should be designed without saturating the magnetic core during both the charging as well as the discharging processes.

\section{Experimental results}

The experimental results of the bi-directional flyback converter are shown in Figs. 4 and 5. Fig. 4 shows the zoomed waveforms during charging and discharging operations respectively, and Fig. 5 shows the waveforms of the continuous charging and discharging operation of the flyback converter for 
the film capacitive load and the DEAP actuator respectively. The charging energy efficiency is defined as, the ratio of energy stored in the capacitive load, to the energy input to the converter during charging process [17]. The discharging energy efficiency is defined as, the ratio of energy recovered back to the source, to the energy input during the discharging process (which is the energy stored in the capacitive load). The charging $\eta_{c h \text { arge }}$ and discharging $\eta_{\text {discharge }}$ energy efficiency expressions are given below.

$$
\begin{gathered}
\eta_{\text {charge }}=\frac{0.5 \cdot C_{\text {out }} V_{\text {out }}^{2}}{\int_{0}^{T_{\text {chatge }}} V_{\text {in }} i_{\text {in_charge }} d t} \\
\eta_{\text {discharge }}=\frac{\int_{T_{\text {dischagge }}}^{T_{\text {chage }}+T_{\text {delay }}} V_{\text {in }} i_{\text {in_discharge }} d t}{0.5 \cdot C_{\text {out }} V_{\text {out }}^{2}}
\end{gathered}
$$

where $T_{\text {charge }}$ and $T_{\text {discharge }}$ are the charging and discharging times of the capacitive load respectively ( $T_{\text {delay }}$ is a delay between the charging and discharging processes). The input supply current during charging is $i_{\text {in_charge }}$ and the recovered input current during discharging is $i_{\text {in_discharge. }}$ The energy efficiency curves are given in Fig. 6.

Table II: Components used in the converter

\begin{tabular}{|c|c|}
\hline Component & Name \\
\hline Low voltage / High voltage MOSFET & STB50NF25 $[250 \mathrm{~V}, 45 \mathrm{~A}, 55 \mathrm{~m} \Omega] /$ \\
& IXTV03N400S $[4 \mathrm{kV}, 300 \mathrm{~mA}, 290 \Omega]$ \\
\hline High voltage diode & SXF6525 $\left[5 \mathrm{kV}, 150 \mathrm{~mA}, 70 \mathrm{~ns}\left(t_{r r}\right)\right]$ \\
\hline
\end{tabular}

Table III: Flyback transformer parameters

\begin{tabular}{|c|c|}
\hline Parameter & Value \\
\hline Primary $\left(L_{m p}\right) /$ Secondary magnetizing inductance $\left(L_{m s}\right)$ & $44 \mu \mathrm{H} / 28 \mathrm{mH}$ \\
\hline Flyback transformer core / Material & $\mathrm{ETD} 29 / \mathrm{N} 87$ \\
\hline Primary turns $\left(N_{p}\right) /$ Turns ratio $(n)$ & $10 / 25$ \\
\hline Leakage inductance of transformer primary $\left(L_{l k p}\right) /$ secondary winding $\left(L_{l k s}\right)$ & $930 \mathrm{nH} / 647 \mu \mathrm{H}$ \\
\hline Secondary winding $\left(C_{s}\right) /$ Inter-winding stray capacitance $\left(C_{i n t}\right)$ & $26 \mathrm{pF} / 26.2 \mathrm{pF}$ \\
\hline DC resistance of primary $\left(R_{p}\right) /$ secondary winding $\left(R_{s}\right)$ & $60 \mathrm{~m} \Omega / 7.6 \Omega$ \\
\hline
\end{tabular}
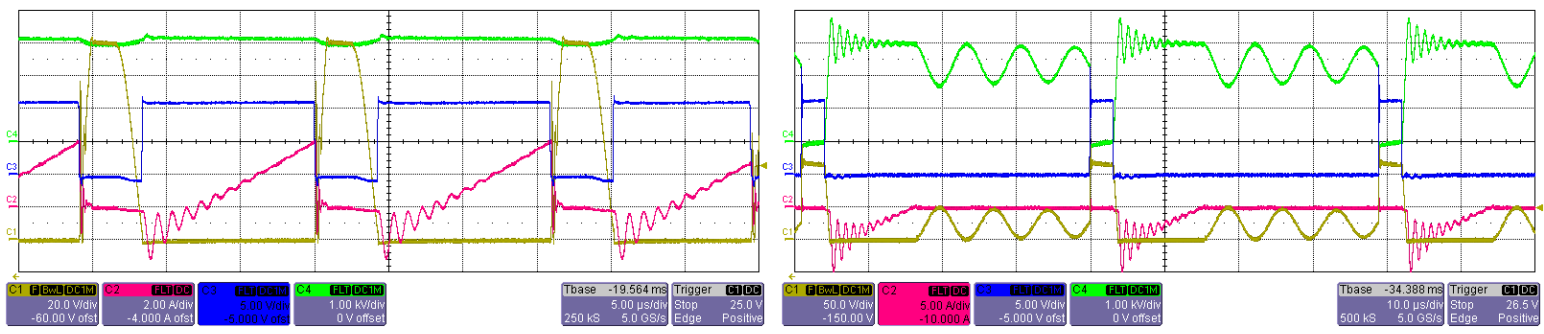

Fig. 4: Zoomed waveforms during charging operation (left)- $\mathrm{CH} 1: V_{\text {drainMl }} ; \mathrm{CH} 2: i_{p} ; \mathrm{CH} 3: V_{\text {GateMl }}$; CH4: $V_{\text {drainM2 }}$ and discharge operation (right)- $\mathrm{CH} 1: V_{\text {drainM1 }} ; \mathrm{CH} 2: i_{p} ; \mathrm{CH} 3: V_{\text {GateM2}} ; \mathrm{CH} 4: V_{D 2}$
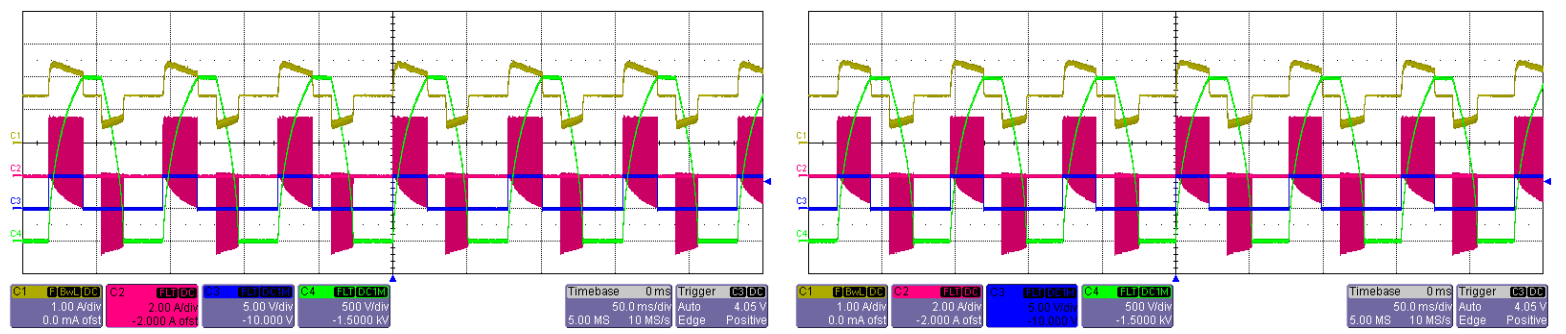

Fig. 5: Continuous bi-directional operation of the flyback converter at $2.5 \mathrm{kV}$ output voltage with film capacitive load (left), and with DEAP actuator (right) - $\mathrm{CH} 1: i_{\text {in }} ; \mathrm{CH} 2: i_{p} ; \mathrm{CH} 3: V_{\text {chargel }}$; $\mathrm{CH} 4: V_{\text {out }}$ 

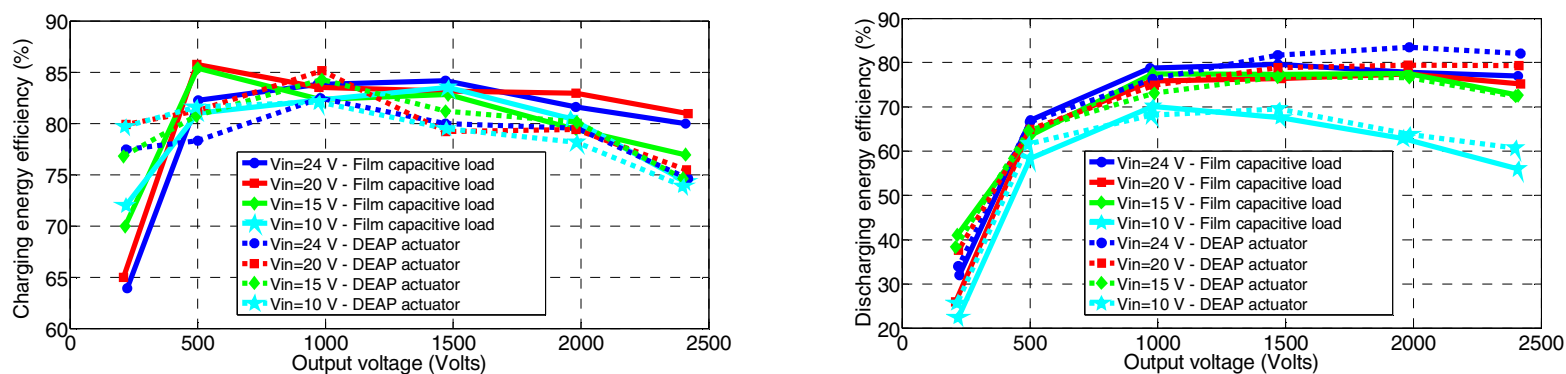

Fig. 6: Charging energy efficiency (left) and discharging energy efficiency curves (right)

\section{Conclusion}

The bi-directional flyback converter was successfully implemented for high voltage capacitor charging application. The converter was operating with $80-85 \%$ charging and $70-80 \%$ discharging energy efficiencies. Careful design of the flyback transformer is required for successful implementation of high voltage bi-directional flyback converter, without damaging the high voltage $4 \mathrm{kV}$ MOSFET.

\section{References}

[1] M. Tryson, H. E. Kiil, M. Benslimane, "Powerful tubular core free dielectric electro activate polymer (DEAP) push actuator," in Proc. SPIE, vol. 7287, p. 72871F, 2009.

[2] R. Pelrine, P. Sommer-Larsen, R. Kornbluh, R. Heydt, G. Kofod, Q. Pei, P. Gravesen, “Applications of dielectric elastomer actuators," in Proc. SPIE, vol. 4329, pp. 335-349, 2001.

[3] http://www.polypower.com

[4] P. Thummala, L. Huang, Z. Zhang, M. A. E. Andersen, "Analysis of Dielectric Electro Active Polymer Actuator and its High Voltage Driving Circuits," in Proc. IEEE IPMHVC, pp. 458-461, Jun. 4-7, 2012.

[5] P. Thummala, Z. Zhang, M. A. E. Andersen, O. C. Thomsen, "A high voltage DC-DC converter driving a Dielectric Electro Active Polymer actuator for wind turbine flaps," in Proc. IEEE UPEC, pp.1-7, 4-7 Sept. 2012.

[6] J. Elmes, C. Jourdan, O. Abdel-Rahman, I. Batarseh, "High-Voltage, High-Power-Density DC-DC Converter for Capacitor Charging Applications," in Proc. IEEE APEC, pp. 433-439, 2009.

[7] T. Andersen, M. S. Rødgaard, O. C. Thomsen, M. A. E. Andersen, "Low voltage driven dielectric electro active polymer actuator with integrated piezoelectric transformer based driver," in Proc. SPIE, vol. 7976, p. 79762 N, 2011.

[8] S. K. Chung, H. B. Shin, "High-voltage power supply for semi-active suspension system with ER-fluid damper," in Proc. IEEE Transactions on Vehicular Technology, vol. 53, no. 1, pp. 206- 214, Jan. 2004.

[9] K. Venkatesan, "Current Mode Controlled Bidirectional Flyback Converter," in Proc. IEEE PESC, pp. 835842, 1989.

[10] T. Bhattacharya, V. S. Giri, K. Mathew, L. Umanand, "Multiphase Bidirectional Flyback Converter Topology for Hybrid Electric Vehicles,", in Proc. IEEE Transactions on Industrial Electronics, vol. 56, no.1, pp.78-84, Jan. 2009.

[11] G. Chen, Y.-S. Lee, S.Y.R. Hui, D. Xu, Y. Wang, "Actively clamped bidirectional flyback converter," in Proc. IEEE Transactions on Industrial Electronics, vol. 47, no. 4, pp. 770-779, Aug. 2000.

[12] S.-S. Hong, S.-K. Ji, Y.-J. Jung, C.-W. Roh, "Analysis and Design of a High Voltage Flyback Converter with Resonant Elements," in Proc. Journal of Power Electronics, vol. 10, no. 2, pp. 107-114, Mar. 2010.

[13]P. Thummala, H. Schneider, Z. Ouyang, Z. Zhang, M. A. E. Andersen, "Estimation of Transformer Parameters and Loss Analysis for High Voltage Capacitor Charging Application," in Proc. IEEE ECCE Asia, pp. 704-710, 3-6 Jun. 2013.

[14] S.-K, Chung, "Transient characteristics of high-voltage flyback transformer operating in discontinuous conduction mode," in IEE Proc. Electric Power Applications, vol.151, no.5, pp.628-634, 9 Sept. 2004.

[15]Linear Technology, "LT3751 High Voltage Capacitor Charger with Regulation", Linear Technology Corporation, USA. http://cds.linear.com/docs/en/datasheet/3751fc.pdf

[16]N. O. Sokal, R. Redl, "Control algorithms and circuit designs for optimal flyback-charging of an energystorage capacitor (e.g., for flash lamp or defibrillator)," in Proc. IEEE Transactions on Power Electronics, vol. 12, no. 5, pp. 885-894, Sep. 1997.

[17] T. Andersen, L. Huang, M. A. E. Andersen, O. C. Thomsen, "Efficiency of capacitively loaded converters," in Proc. IEEE IECON, pp. 367-372, 2012. 